\title{
Sprouty is a cytoplasmic target of adenoviral E1A oncoproteins to regulate the receptor tyrosine kinase signalling pathway
}

\author{
Angelika Zaremba ${ }^{1 *}$, Ursula Schmuecker $^{2}$ and Helmut Esche ${ }^{2}$
}

\begin{abstract}
Background: Oncoproteins encoded by the early region of adenoviruses have been shown to be powerful tools to study gene regulatory mechanisms, which affect major cellular events such as proliferation, differentiation, apoptosis and oncogenic transformation. They are possesing a key role to favor viral replication via their interaction with multiple cellular proteins. In a yeast two-hybrid screen we have identified Sprouty1 (Spry1) as a target of adenoviral E1A Oncoproteins. Spry proteins are central and complex regulators of the receptor tyrosine kinase (RTK) signalling pathway. The deregulation of Spry family members is often associated with alterations of the RTK signalling and its downstream effectors, leading to the ERK pathway.

Results: Here, we confirm our yeast two-hybrid data, showing the interaction between Spry1 and E1A in GST pulldown and immunoprecipitation assays. We also demonstrated the interaction of E1A with two further Spry isoforms. Using deletion mutants we identified the N-terminus and the CR conserved region (CR) 3 of E1A- and the C-terminal half of Spry1, which contains the highly conserved Spry domain, as the essential sites for direct interaction between Spry and E1A. Immunofluorescent microscopy data revealed a co-localization of E1 $A_{13 s}$ with Spry 1 in the cytoplasm. SRE and TRE reporter assays demonstrated that co-expression of Spry 1 with E1 $A_{13 S}$ abolishes the inhibitory function of Spry1 in RTK signalling, which is consequently accompanied with a decrease of



Conclusions: These results establish Spry1 as a cytoplasmic localized cellular target for E1A oncoproteins to regulate the RTK signalling pathway, and consequently cellular events downstream of RTK that are essential for viral replication and transformation.
\end{abstract}

\section{Background}

Proteins encoded by the early transcription unit $1 \mathrm{~A}$ (E1A) of Adenovirus (Ad) are essential for the viral life cycle because of their necessity in regulating the expression of all other viral genes [1]. In addition these proteins modulate the expression of specific cellular genes in infected cells to facilitate viral reproduction [2,3]. E1A oncoproteins cooperate with Ad early region 1B (E1B) oncogene products to transform rodent cells in culture and, depending on the serotype, to induce tumors in immunocompetent animals (e.g. Ad12) [4-6]. Ad12 E1A

\footnotetext{
* Correspondence: zarembaa@niehs.nih.gov

1 Laboratory of Signal Transduction, National Institute of Environmental Health Sciences, Research Triangle Park, PO Box 12233, Durham, NC 27709, USA

Full list of author information is available at the end of the article
}

gives rise to five proteins of which the $266 \mathrm{R}$ protein (translated from a 13S mRNA; henceforth referred to as




nant isoforms [2,7]. Both proteins are translated in the same reading frame but differ in a short stretch of 31 aa,


E1A regions (CR1, CR2, CR3 and CR4) that are highly conserved among all Adenovirus serotypes [2]. The $\mathrm{N}$ terminus and the CRs of E1A mediate most of the gene regulatory functions necessary for viral reproduction and transformation [8]. Due to the lack of a sequence-specific DNA binding activity, E1A proteins, mainly known as transcription factors, fulfill their gene regulatory functions by interaction with cellular transcription factors

\section{Biomed Central}


such as c-Jun, ATF, CREB, or repressors such as $\mathrm{pRB}$ and cellular co-factors like p300 and CBP [9-12].

The idea that E1A is also capable of exerting its regulatory functions by directly affecting cytoplasmic processes was supported by the discovery that a certain amount of E1A proteins is acetylated at Lys ${ }^{239}$, which determines the cytoplasmic localization of E1A proteins by interfering with the nuclear transport [13]. Until now, a few cytoplasmic localized interaction partners of E1A have been identified including the regulatory subunit II of protein kinase A (PKA-RII $\alpha$ ) [14], the receptor for activated C-kinase l (Rackl) $[15,16]$, and the cytoplasmic proteasome 26S [17].

Sprouty (Spry) proteins have been identified as regulatory proteins of the receptor tyrosine kinase (RTK) signalling pathway [18-21]. They appear to play an inhibitory role in many cellular events due to their effect on RTK, especially in FGF-dependent developmental processes [22-25]. First identified in Drosophila [19], Sprouty homologues have been discovered in human and mouse. A high degree of conservation of key functional amino acids has been shown for Spry proteins among different species [20,22,26,27].

A unique and highly conserved C-terminal cysteine-rich Spry domain has been identified for all 4 mammalian Spry isoforms. The Spry domain is responsible for palmitoylation at the plasma membrane. Mutations in this region disrupt membrane localization and abrogate Spry functions $[22,28,29]$. A conserved short N-terminal tyrosinecontaining motif of Spry was discovered to be critical for physiological functions to inhibit FGF signalling and sustain EGF signalling [30,31]. Different interacting partners have been identified, which upon binding with Spry consequently influence RTK signalling pathway, including Rafl, Grb2, c-Cbl and Shp2 [28,31-33]. The deregulation of Sprouty was described in a number of cancers [34-38].

In a search to identify potential cytoplasmic binding partners of Adenovirus E1A oncoproteins we detected Spry1 as a putative binding partner of E1A. We were able to confirm this interaction in GST pull-down and immunoprecipitation assays. We also demonstrated an interaction of two further Spry isoforms with E1A and characterized the protein domains that are responsible for binding. Using confocal immunofluorescence microscopy, we detected a co-localization of Spry1 and E1 $\mathrm{A}_{13 \mathrm{~S}}$ exclusively in the cyto-


functional role for this interaction to modulate RTK signalling pathway and thereby to regulate cellular processes.

\section{Results}

\section{Sprouty proteins interact with E1A isoforms}

In a previous search for cellular targets of adenoviral proteins using a mouse embryo cDNA-expression library (Chevrayx and Nathans, Howard Huges Medical
Institute, Baltimore) and a SOS-yeast two hybrid system we detected mouse Spry1 as a cytoplasmic interaction partner of Ad12 E1A proteins (data not shown). In order to confirm this observation, we first examined the binding of Spry1 and further Spry proteins with Ad12 E1A isoforms by GST pull-down assays. Mouse Spry1, Spry2 and Spry4 were exogenously expressed in HeLa cells and

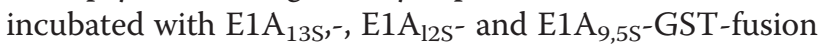
proteins (Figure 1A). Spry1 and Spry4 interact with all three Ad12 E1A isoforms (Figure 1B). For Spry2 we were not able to detect an interaction with $\mathrm{E}_{12} \mathrm{~A}_{12 \mathrm{~S}}$ and $\mathrm{E}_{1} \mathrm{~A}_{9.5 \mathrm{~S}}$ showed only weak binding. The mutant $\triangle \mathrm{NE} 1 \mathrm{~A}_{12 \mathrm{~S}}$, an isoform where we deleted the first 29 amino acids of the $\mathrm{N}$ terminus, showed no interaction with Spry1 and Spry2 (Figure 1B). However, for Spry4 we were able to detect an interaction with $\triangle \mathrm{NE} 1 \mathrm{~A}_{12 \mathrm{~S}}$, indicating an essential function of the Ad12 E1A N-terminal domain for efficient interaction with Spry1 and Spry2. Although weak, we surprisingly detected an interaction between Spry1 and the analog aminoterminal deletion mutant of the $\mathrm{E} \mathrm{A}_{13 \mathrm{~S}}$ isoform, indicating that the conserved region 3 (CR3) is also involved in binding with Spry1. However the domain of E1A that is responsible for the interaction with Spry4 remains to be elucidated. To further define the region of Spry1 that is necessary for binding with E1A we constructed two deletion mutants in which we truncated either the $\mathrm{N}$-terminal $(\Delta \mathrm{NSp} p \mathrm{1} 1)$ or the $\mathrm{C}$ terminal half of Spry1 ( $\Delta$ CSpry1) (Figure 1A). Our data showed that the C-terminal half of Spry1, bearing the highly conserved Spry domain, is necessary for the interaction with E1A, whereas the tyrosine-containing sequence of the $\mathrm{N}$-terminal part is not essential for interaction (Figure $1 \mathrm{C}$ ). Since the Spred family of proteins are likewise Sprouty-domain-containing proteins that show regulatory functions in RTK signalling pathway [39,40], we studied the interaction of E1A proteins with mouse Spred 1 and Spred2 by GST pull-down assays. In our experiments, we were not able to detect any interactions between Spred proteins and E1A isoforms (data not shown). It's possible that conformational changes due to additional binding domains [such Ena/Vasp homolog $(\mathrm{EVH}) 1$ and c-Kit binding (KBD)-domain] in Spred proteins prevent E1A from binding with this protein family [20].

To confirm whether the interaction of E1A with Spry occurs in cells we co-expressed Spry1 and Myc-tagged $\mathrm{E}_{1} \mathrm{~A}_{12 \mathrm{~S}}$ proteins in HeLa cells. Cell lysates were subjected to immunoprecipitation with anti-Spry1 antibody, and the immunoprecipitates were then analyzed for the presence of Myc-tagged E1 $\mathrm{A}_{12 \mathrm{~S}}$. Results from these experiments have confirmed that $\mathrm{E}_{1} \mathrm{~A}_{12 \mathrm{~S}}$ binds Spry1 in mammalian cells (Figure 1D).

To verify if the interaction with Spry proteins is restricted to E1A proteins of the highly ongogenic 




Figure 1 Sprouty proteins interact with E1A isoforms. (A) Schematic representation of the E1A wild type isoforms E1 A 135 , E1A 125 , E1 A9.5s, the deletion mutants $\triangle N E 1 A_{13 s}$ and $\triangle N E 1 A_{12 S}$ (with a deletion of the first $29 \mathrm{~N}$-terminal amino acids) and Spry isoforms and deletion mutants ( $\triangle$ NSpry 1 with a deletion of amino acids 1-173; $\triangle$ CSpry1 with a deletion of amino acids 174-313). Red boxes in E1A proteins represent the conserved regions 1 to 4; the brown box in Spry represents the Spry domain and the blue box the conserved tyrosine phosphorylation site. (B, C) For GST pull-down assays HeLa cell extract, containing the isoform Spry1, Spry2 or Spry4 (B) or the Spry-mutants $\triangle$ NSpry1 or $\triangle$ CSpry1 (C) were incubated with the protein leader sequence GST- or GST-E1A-fusion proteins as indicated. $0.5 \mathrm{mg}$ of cellular lysate and $40 \mu \mathrm{gg}$ of GST-E1A or GST were incubated at $4^{\circ} \mathrm{C}$ for $1 \mathrm{~h}$. Proteins bound were subjected to SDS-PAGE, and immunoblot analysis was performed with antibodies directed against the Myc-epitope of Spry-fusion proteins. * The higher molecular weight band may represent post-translational modification of Spry 1 (palmitoylation and phosphorylation) as reported before [22]. (D) For immunoprecipitation HeLa cells were transiently co-transfected with Spry1 and Myc-tagged E1 $1 \mathrm{~A}_{125}$ expression vectors as indicated. Cell extracts were prepared $48 \mathrm{~h}$ post transfection and incubated with anti-Spry 1 antibodies. Interacting proteins were precipitated and analyzed on SDS-PAGE by Western blotting using anti-Spry 1 and anti-Myc antibodies. Transient expression was examined in the total lysate ( $\triangle$ co-eluted antibody heavy chains). 
adenovirus serotype 12 (Ad12), we examined the interaction of the non-oncogenic adenovirus serotype 2 (Ad2) $\mathrm{E}_{1} \mathrm{~A}_{13 \mathrm{~S}}$ protein with Spry1 and were able to detect an interaction (Figure 2A).

\section{Spry1 interacts with the Human papillomavirus type 16 (HPV16) E7 protein}

The E7 oncoprotein of the Human Papillomavirus type 16 (HPV16-E7) displays partial amino acid sequence homology, comparable function, and similar interaction partners with adenoviral E1A oncoproteins [41,42]. Therefore, we examined and confirmed the interaction of Spry1 with the HPV16-E7 protein by GST pull-down assay (Figure 2B). As a positive control we used GST-


pull down assay. Our results establish Spry proteins as potential targets of presumably various DNA tumor virus oncoproteins.

\section{Spry1 co-localizes with $\mathrm{E}_{1} \mathrm{~A}_{13 \mathrm{~s}}$ in the cytoplasm}

To determine the subcellular localization of Spry1 in the presence of E1A proteins, we performed confocal immunofluorescence microscopy using antibodies that specifically recognize Spry1 and Myc-tagged E1A 135 . HeLa cells were serum-deprived overnight and treated with bFGF for $2 \mathrm{~h}$. Whereas Spry1 was distributed within the whole cytoplasm, $\mathrm{E}_{1 \mathrm{~A}_{13 \mathrm{~S}}}$ was predominantly found in the nucleus (Figure 3 ) with a lesser amount of E1 $\mathrm{A}_{13 \mathrm{~S}}$



Figure 2 Spry 1 interacts with $\mathrm{E}_{1} \mathrm{~A}_{13 \mathrm{~s}}$ of the non-oncogenic Adenovirus type 2 ( $\mathrm{Ad} 2$ ) and with the Human papillomavirus type 16 (HPV16) E7 protein. Lysates from cell extracts expressing Spry1 were incubated with (A) GST-Ad2-E1 A 13 s and (B) GST-HPV16E7-fusion proteins or for control reactions with the leader sequence GST or GST-Ad12-E1 $A_{135}$ as indicated. The assays were performed with $0.5 \mathrm{mg}$ of cellular lysate and $40 \mu \mathrm{g}$ of GST-fusion proteins at $4^{\circ}$ $\mathrm{C}$ for $1 \mathrm{~h}$. The bound proteins were subjected to SDS-PAGE and analyzed by immunoblotting. Spry 1 was detected by an antibody directed against the Myc-epitope of the Spry-fusion protein. detectable in the cytoplasm. This cytoplasmic pool of E1 $_{13 S}$ strongly co-localized with Spry1, predominantly in vesicular structures within the cytoplasm (Figure $3 \mathrm{C}$ ). In addition, the subcellular localization of Spry1 is not affected by the presence of E1A proteins.

\section{Co-expression of Spry1 decreases E1 $\mathrm{A}_{13 \mathrm{~s}}$-induced gene transactivation of TRE and SRE}

In transient expression assays we examined the effect of Spry1 and $\mathrm{E}_{1} \mathrm{~A}_{13 \mathrm{~S}}$ interaction on gene expression activity. First, we analyzed this effect on the TPA-responsive element (TRE) in HeLa cells, which is transactivated by E1A and c-Jun $[43,44]$. Our results showed that the expression of the collagenase $(\mathrm{Col})-\mathrm{TRE}$ driven reporter gene is down-regulated after Spry1 expression and up-regulated due to the ectopic expression of $E 1 A_{13 S}$, whereas it is highly up-regulated when $\mathrm{E}_{1} \mathrm{~A}_{13 \mathrm{~S}}$ and c-Jun are co-

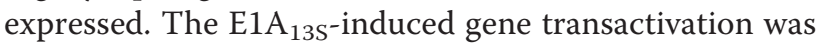
again repressed by co-expression with Spry1 (Figure 4). These data indicate that Spry1 decreases E1 $\mathrm{A}_{13 \mathrm{~S}}$-induced gene expression. Because Spry1 is known to act as a repressing factor in RTK signalling pathways, it is conceivable that co-expression of Spry1 represses E1A-induced gene expression by inhibiting the activity of specific kinases involved in transcriptional activation. To gain further insight into how the direct interaction of $\mathrm{E}_{1 \mathrm{~A}} \mathrm{~A}_{13 \mathrm{~S}}$ with Spry1 functionally influences gene transactivation we decided to choose another reporter construct. The serum response element (SRE) is known to be downregulated by Spry proteins in response to bFGF treatment $[23,45]$. In our experiments cells were serum deprived for $24 \mathrm{~h}$ prior to stimulation with $10 \%$ FCS or $20 \mathrm{ng} / \mathrm{ml}$ bFGF for 1, 5, 7 and 9 hours. In HeLa cells, we detected a 2 to 3 fold increase in reporter gene activation in response to $\mathrm{E}_{1 \mathrm{~A}} \mathrm{~A}_{13 \mathrm{~S}}$ expression after 5 - $9 \mathrm{~h}$ incubation with FCS, whereas in C33A and NIH-3T3 cell lines an upregulation of promoter activity by $\mathrm{E} \mathrm{A}_{13 \mathrm{~S}}$ was already detectable after $1 \mathrm{~h}$ of FCS stimulation (Figure 5). Similar results were obtained using bFGF instead of FCS for induction of the RTK signalling pathway after serum deprivation (Figure 6A). In cells that express both proteins, $\mathrm{E} \mathrm{A}_{13 \mathrm{~S}}$ abolishes the repression function of Spry1, whereby the E1 $\mathrm{A}_{13 \mathrm{~S}}$-induced gene expression activity consequently decreases by up to more than $50 \%$. Concentration-dependent reporter assays showed a decrease of


Spry1 co-expression. Whereas the ability of Spry1 to reduce gene expression activity is abolished in response to an increase of $\mathrm{E}_{1 \mathrm{~A}} \mathrm{~A}_{13 \mathrm{~S}}$ co-expression (Figure 7).

In co-expression experiments in which we expressed E1 $A_{12 S}$ instead of E1 $A_{13 S}$ however, we could not detect an increase in SRE-promoter activity and therefore no significant change after co-expression of Spry1 as well (data not shown). 




Spry1



$\mathrm{E} 1 \mathrm{~A}_{13 \mathrm{~S}}$



Merged


confocal immunofluorescence microscopy using antibodies that specifically recognize Spry1 (green) and the Myc-tagged E1 $\mathrm{A}_{13 \mathrm{~s}}$ (red) protein constructs. (A) Spry1 and (B) E1 $\mathrm{A}_{13 \text { s }}$ transfected cells were left serum starved overnight and stimulated with 20 ng/ml bFGF for 2 h. (C) Images were overlaid for comparison of staining, yellow indicates co-localization of the two proteins. Scale bar, $10 \mu \mathrm{m}$.

Using the E1A $13 \mathrm{~S}$-terminal deletion mutant $\left(\triangle \mathrm{NE} \mathrm{A}_{13 \mathrm{~S}}\right)$ in such transient expression assays, we were unable to detect a decrease of $\triangle \mathrm{NE} 1 \mathrm{~A}_{13 \mathrm{~S}}$ induced gene expression in response to Spry1 compared with studies using wild type E1 $\mathrm{A}_{13 \mathrm{~S}}$ (Figure 6). Also, the co-expression of $\triangle \mathrm{NE}_{1 \mathrm{~A}} \mathrm{~A}_{13 \mathrm{~S}}$ with Spry1 after $7 \mathrm{~h}$ and $9 \mathrm{~h}$ of stimulation showed a slightly higher SRE-dependent gene expression compared with cells expressing $\triangle \mathrm{NE}_{1} \mathrm{~A}_{13 \mathrm{~S}}$ exclusively. Our GST pull-down data showed that Spry1 interacts only weakly with $\triangle \mathrm{NE}_{1 \mathrm{~A}}$, suggesting that the stronger interaction with Spry1 mediated by the $\mathrm{N}$-terminus of E1A might be necessary for the inhibitory effect of Spry1 to repress $\mathrm{E} \mathrm{A}_{13 \mathrm{~S}}$ activity. Moreover it is worthwhile to note that these data also show that SRE can be activated by $\mathrm{E} 1 \mathrm{~A}_{13 \mathrm{~S}}$ independent of its $\mathrm{N}$-terminal amino acids.

\section{Co-expression of Spry1 and $\mathrm{E}_{1} \mathrm{~A}_{13 \mathrm{~s}}$ specifically impairs phosphorylation of ERK1/2 MAP kinase}

It is reported that Spry1 inhibits the Ras/Raf/MAP kinase pathway [23]. To examine if the SRE-dependent reporter gene expression is affected by the ERK1/2 MAP kinase pathway, we analyzed the phosphorylation of ERK1/2 in HeLa cells after expression of Spry1 and


ERK1/2 was detected in cells expressing Spry1, as compared with cells that were transfected with an empty expression plasmid, when visualized by phospho-specific antibodies. Expression of $\mathrm{E}^{1 \mathrm{~A}_{13}}$ in these cells led to an increased phosphorylation of ERK1/2 after $1 \mathrm{~h}$ of bFGF treatment, whereas the addition of Spry1 inhibited ERK1/2 phosphorylation (Figure 6C). For comparison we assayed the influence of $\triangle \mathrm{NE}_{1} \mathrm{~A}_{13 \mathrm{~S}}$ on ERK1/2 phosphorylation in the presence of Spry1. As expected, we were not able to detect an inhibition of the ERK1/2 phosphorylation/activation after co-expression of Spry1 and $\triangle N E 1 A_{13 S}$ (Figure $6 \mathrm{C}$ ). Confirming the SRE reporter assays, a slight increase in phosphorylation was detectable in cells expressing Spry 1 and $\triangle \mathrm{NE}_{1} \mathrm{~A}_{13 \mathrm{~S}}$ compared to cells only expressing $\triangle \mathrm{NE}_{1 \mathrm{~A}} \mathrm{~A}_{13 \mathrm{~S}}$. To summerize, these results support our hypothesis of a functional interaction between E1A oncoproteins and Spry1 in the cytoplasm to modulate the Ras/Raf/MAP kinase pathway.

\section{Discussion}

E1A oncoproteins have a key role in adenoviral replication. Their specific interaction with cellular proteins induces viral and cellular gene expression which initiates the host cell to enter S-Phase and therefore enables the virus life cycle to continue [46]. E1A binding partners are therefore specific targets that enable the virus to modulate the cell cycle. In this study, we identified Spry proteins as cytoplasmic interacting partners of adenoviral E1A proteins. Since Spry proteins are known as the "regulator" of RTK signalling pathway we studied and demonstrated the ability of E1A to modulate RTK signalling pathway through specific interaction with Spry1.

The mammalian Spry family consists of four Spry proteins. In our GST pull-down assays we showed differences in binding affinity of E1A isoforms with specific Spry family members (Spry1, Spry2, Spry4) which might reflect various interaction mechanisms and potential differences in functions of Spry isoforms. Here we observed a strong binding of Ad12 E1A proteins with Spry1 and Spry2, mediated via the aminoterminal E1Asequence and furthermore the responsibility of CR3 for a less strong interaction with Spry1. Interestingly, the 




C

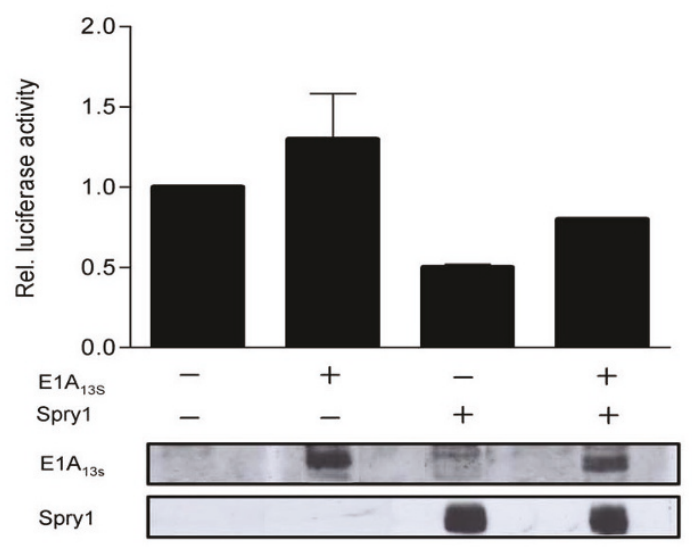

Figure $4 \mathrm{E}^{\mathrm{A}} \mathrm{A}_{13}$ inhibits Spry 1 down-regulation of the Col-TRE driven reporter gene. (A) Schematic representation of the reporter construct 3xcolTRE-tk-Luc; the Luciferase expression is driven by the thymidine kinase promoter of the herpes simplex virus (tk, nt -105 to +51 ) and three copies of the TRE sequence of the human collagenase gene (colTRE, nt -73 to -65). (B, C) HeLa cells were cotransfected with the colTRE-Luc reporter construct $(0.5 \mu \mathrm{g})$, expression vectors $(0.5 \mu \mathrm{g})$ coding for $\mathrm{E}_{1 \mathrm{~A}} \mathrm{~A}_{13 \mathrm{~s}}$ and/or Spry 1 and cJun as indicated. Empty expression vectors were added to keep the amount of transfected DNA constant. $63 \mathrm{~h}$ after transfection cells were lysed and Luciferase activity was determined. Total lysates were immunoblotted to monitor the presence of expressed proteins with respective antibodies against E1 $\mathrm{A}_{135}$, Spry 1 and c-Jun. Results are mean \pm S.E.M. between duplicates. less conserved N-terminal sequence of the Ad12 E1A proteins is responsible for the interaction with two further cytoplasmic proteins, the $26 \mathrm{~S}$ proteasom and the PKA-RII $\alpha[14,17]$. However, the amino acids involved in the interaction of these proteins are still unknown. Moreover we discovered the C-terminal half of Spry1, including the Spry domain, as the responsible region for E1A interaction. However, the Spry-domain-containing Spred proteins showed no interaction with E1A. It has yet to be clarified whether Spry-domain-neighbouring amino acids or variable amino acids within the conserved Spry domain mediate the interaction with E1A. Conformational changes between Spry and Spred proteins due to their Ena/Vasp homolog (EVH)1 and c-Kit binding (KBD)-domain, which is missing in Spry, may prevent E1A from binding [20].

We detected Spry1 accumulated and associated with $\mathrm{E}_{1} \mathrm{~A}_{13 \mathrm{~S}}$ in vesicular structures within the whole cytoplasm. A localization of Spry proteins in vesicular structures has been reported before [22,47]. Palmitoylation targets Spry to the plasma membrane, which has been shown to be a necessary step for the inhibitory function of Spry in RTK signalling pathway [22,29].

Using TRE or SRE luciferase reporter assays we analyzed the functional consequences on gene expression activity by

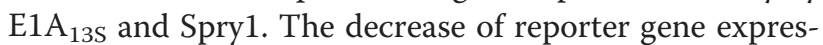
sion by Spry1 was abolished when co-expressed with $\mathrm{E}_{1} \mathrm{~A}_{13 \mathrm{~s}}$. Expression of constant amounts of Spry1 and increasing amounts of $\mathrm{E} 1 \mathrm{~A}_{13 \mathrm{~S}}$ proteins showed that Spry1 proteins are functionally inactivated by $\mathrm{E} \mathrm{A}_{13 \mathrm{~S}}$ and vice versa. A functional repression of Spry1 would lead to an increasing activity of the RTK signalling pathway and to an increasing amount of phosphorylated transcription factors which could therefore enhance E1A-induced gene expression. This observation was supported by our experiments analyzing the phosphorylation of ERK. Overexpression of Spry1 decreased E1 $\mathrm{A}_{13 \mathrm{~s}}$-induced ERK-phosphorylation in comparison to the expression of E1A alone.

The up- or down-regulation of Spry has been described in different cancers [48], indicating the necessity of a balanced function of Spry proteins. Our data indicate that Spry1 is an important target of E1A proteins in the cytoplasm to modulate the RTK signalling pathway to influence cellular processes for optimizing viral replication.

Using the aminoterminal deletion mutant of $\mathrm{E} 1 \mathrm{~A}_{13 \mathrm{~S}}$ we obtained unexpected data. $\triangle \mathrm{NE} \mathrm{A}_{13 S}$ displays only a weak binding with Spry1 via the CR3 in GST pull-down assays (Figure 1B) and can still increase reporter gene expression, whereas in co-expression with Spry1 no significant repression was detectable (Figure 6B). Possibly, the interaction via the CR3 has different effects on 
A



B



D



C



Figure 5 Spry1 decreases E1 $A_{13 s}$ induced SRE transactivation in different cell lines. (A) HeLa cells, (B) C33A cells and (C) NIH-3T3 cells were co-transfected with the SRE-Luc reporter construct $(1 \mu \mathrm{g})$ and with plasmids $(0.5 \mu \mathrm{g})$ expressing E1 $\mathrm{A}_{13 \mathrm{~s}}$ and/or Spry 1 as indicated. Empty expression vectors were added to keep the amount of transfected DNA constant. After transfection cells were left serum-deprived for $24 \mathrm{~h}$ and then incubated with 10\% FCS in DMEM. Serum stimulation was performed for the indicated times (white, 1 h; cross line, 5 h; horizontal line, 7 h; dots, $9 \mathrm{~h}$ ). The promotor activity of the reporter gene in the presence of empty vectors was set as 1. (D) Expression of Spry 1 and E1 $\mathrm{A}_{135}$ in the lysates was confirmed in Western blot assays. Results are mean \pm S.E.M. between duplicates and representative for 3 individual experiments. 


\section{A}


B
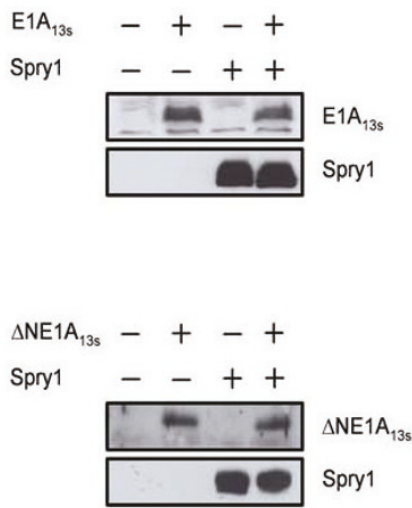

C
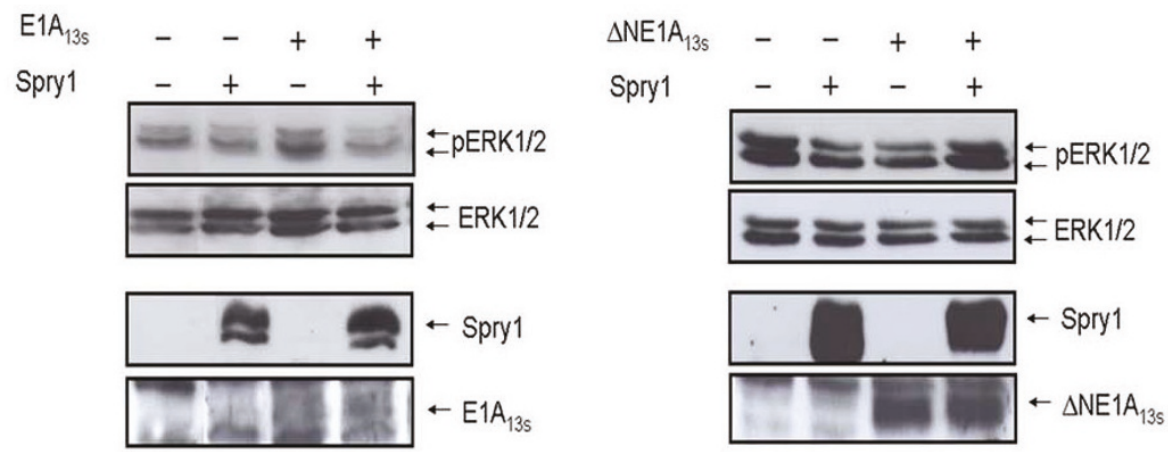

Figure 6 Spry 1 decreases wild type E1 $A_{13 s}$ induced gene expression but not $\Delta N 1 A_{13 s}$ transactivation through ERK1/2 kinase phosphorylation. (A) HeLa cells were co-transfected with the reporter construct SRE-Luc $(1 \mu \mathrm{g})$ and plasmids $(0.5 \mu \mathrm{g})$ expressing Spry 1 and/or


cells were left serum-deprived for $24 \mathrm{~h}$ and then incubated with $20 \mathrm{ng} / \mathrm{ml}$ bFGF in DMEM. Serum stimulation was performed for the indicated times (white, 1 h; cross line, 5 h; horizontal line, 7 h; dots, 9 h). The promotor activity of the reporter gene in the presence of empty vectors was set as 1. Data represents mean \pm S.E.M. of $n \geq 4 .{ }^{*} p<0.05$ (B) Expression of Spry1 and E1 $A_{13 S}$ in the lysates was confirmed in Western blot assays. (C) HeLa cells expressing Spry1 and/or E1 $A_{13 S}$ or $\triangle N E 1 A_{13 s}$ were serum starved overnight, followed by incubation for $1 \mathrm{~h}$ with $20 \mathrm{ng} / \mathrm{ml}$ bFGF in DMEM. Cells were lysed and lysates were subjected to SDS-PAGE and analyzed by immunoblotting. The membranes were incubated with antibodies directed against phosphorylated ERK1/2 (phospho-ERK1/2), unphosphorylated ERK1/2 (ERK1/2) and antibodies directed against Spry1 and E1A 13 s. 


\section{A}



B



Spry1 function compared to the combined interaction via the $\mathrm{N}$-terminus and the CR3 domain of $\mathrm{E}_{1} \mathrm{~A}_{13 \mathrm{~s}}$. These results were also supported by our phosphorylation studies of ERK, indicating an important N-terminal-dependent function of Ad12 E1A proteins for the interaction with Spry1. It is conceivable that the interaction mediated exclusively via the CR3 has a different effect on Spry1 function than the interaction mediated via the $\mathrm{N}$-terminus and the CR3 domain of $\mathrm{E}_{1} \mathrm{~A}_{13 \mathrm{~S}}$. Instead of acting exclusively as inhibitors in signal transduction Spry proteins can be also involved in sustaining signal activity. This function dependents on the activity of binding partners such as c-Cbl $[31,49,50]$. The transcriptional gene expression activity of $\triangle \mathrm{NE} \mathrm{A}_{13 \mathrm{~S}}$ and the interaction of Spry1 exclusively with the CR3 of $\mathrm{E}_{1} \mathrm{~A}_{13 \mathrm{~S}}$ might cause a different influence on Spry1 function and would therefore explain our results using the E1A deletion mutant. Further studies are necessary to understand the mechanism of interaction between E1A and Sprouty proteins in detail.

\section{Conclusion}

In conclusion, our results show for the first time that Spry proteins are targets of adenoviral E1A oncoproteins, which enables the virus to modulate the RTK signalling, leading to the ERK pathway, and to control, in 
addition to its transcriptional functions, cellular processes like proliferation, differentiation and apoptosis. The fact that Spry1 interacts with E7 of HPV 16 leads to the speculation that this might be a more general way of DNA viruses to modulate RTK signalling pathways. Over the past few years increasing evidence is implicating Spry in tumorgenesis and cancer [34,35,38]. Our identification and analysis of the functional interaction between the viral oncoprotein E1A and Spry support the idea of Spry being an important factor in tumorgenesis.

\section{Methods}

\section{Cells, Growth Factors, Transfection Methods}

HeLa, C33A and NIH-3T3 cells were cultured in Dulbecco's modified Eagle's medium with $10 \%$ fetal calf serum (FCS). For GST pull-down assay mouse Spry1, Spry2 and Spry4 were transfected by electroporation with the ECM830 electroporator. Cells were transfected by TransFectin Lipid reagent (Biorad) for co-immunoprecipitation and luciferase assays. For growth factor stimulation, cells were washed and maintained in serum-reduced medium (Dulbecco's modified Eagle's medium with 0.5\% newborn calf serum) for $24 \mathrm{~h}$ prior to fetal calf serum/ bFGF (Invitrogen) treatment. Cells were harvested after several hours as indicated.

\section{DNA Constructs}

The nucleotide sequence of murine Spry1, Spry2 and Spry4 are listed under AF176903, AF176905 and AF176906, respectively. Myc-tagged mouse Spry1 and Spry2 cDNAs cloned in plasmid pSG9M were a gift of Prof. G. Christofori (Basel, Swizerland) and the Myc-tagged mouse Spry4 cDNA cloned in plasmid pcDNA3 was a gift of Prof. A. Yoshimura (Fukuoka, Japan). Nucleotide sequences of GST-E1A-fusion proteins were cloned into the vector pGEX-2t (Pharmacia Biotech). Vector GST-E7pGEX-2t expressing the E7 protein of HPV16 was a gift of Prof. D.J. McCance (Rochester, New York). The N-terminal (residues 1-173) and C-terminal (residues 173-313) DNA fragments of mouse Spry1 and the Adenovirus E1A deletion mutants


235 ) were generated using standard polymerase chain reaction and molecular cloning methods. For co-immunoprecipitation, Spry1 was cloned via BamHI-XhoI sequences into


cloned via BamHI sites into the vector pcDNA3.1/myc-His (-)B (Invitrogen). Mouse c-Jun was purchased from rzpd (clone ID: IRAVp968D0544D) and was cloned into the vector pcR3.1 (Invitrogen). The pGL3/Col-TRE reporter construct contains three colTRE-elements followed by the tk promoter of the herpes simplex virus, and the pGL3/ SRE-Luc reporter construct contains five serum response elements (Stratagene). All constructs were sequenced.

\section{Immunoblot Analysis}

Cells were lysed (10 mM Tris, $\mathrm{pH} 7.4,5 \mathrm{mM} \mathrm{MgCl} 2,150$ $\mathrm{mM} \mathrm{NaCl}, 0.5 \% \mathrm{NP} 40,1 \mathrm{mM}$ 4-(2-Aminoethy1)-BenzeneSulfonylfluorideCl (Pefabloc SC) (Biomol)), proteins were separated by SDS-PAGE and transferred to Hybond-C Extra nitrocellulose membrane (Amersham Bioscience). The following primary antibodies were used: mouse monoclonal anti-Myc (Invitrogen); rabbit polyclonal antiSprouty1 (H120; Santa Cruz); rabbit polyclonal anti-c-JUN (H-79; Santa Cruz); rabbit anti-Ad12E1A antiserum (Genovac); rabbit polyclonal anti-phospho-p44/42 MAP kinase (\#9101; NEB); rabbit polyclonal anti-p44/42 MAP kinase (\#9102; NEB). For detection, one of the following second antisera were used: peroxidase goat anti-mouse IgG $(\mathrm{H}+\mathrm{L})$ (Pierce) at 1/50000; peroxidase goat anti-rabbit IgG $(\mathrm{H}+\mathrm{L})$ (Pierce) at 1/50000. Membranes were developed using ECL (Pierce; Amersham Pharmacia Biotech).

\section{GST pull-down assay}

Glutathione Sepharose 4B was purchased from Amersham Bioscience. For preclearing, $0.5 \mathrm{mg}$ of cellular lysate were incubated with $50 \mu \mathrm{l}$ of Glutathion Sepharose (50\%) for 1 $\mathrm{h}$ at $4^{\circ} \mathrm{C}$. Subsequently, after washing by centrifugation at $500 \times \mathrm{g}$ for $5 \mathrm{~min}$, supernatants were incubated with $40 \mu \mathrm{g}$ of GST-fusion protein for $1 \mathrm{~h}$ at $4^{\circ} \mathrm{C}$. The proteins bound were subjected to SDS-PAGE and immunoblot analysis was performed as described above.

\section{Co-Immunoprecipitation}

Cells were lysed with RIPA buffer (Santa Cruz) and precleared with control IgG (Santa Cruz) and $20 \mu$ lof Protein A/G Plus-agarose (Santa Cruz). $0.5 \mathrm{mg}$ of the cell lysates were incubated with $1.6 \mu \mathrm{g}$ of the precipitating antibody for $1.5 \mathrm{~h}$ at $4^{\circ} \mathrm{C}$ while gentle rocking. $20 \mu \mathrm{l}$ of Protein A/G Plus-agarose were added for overnight incubation. The beads were collected by centrifugation, washed 3 times with $1 \mathrm{ml}$ of lysis buffer, and boiled in $40 \mu \mathrm{l} 2 \times$ SDS sample buffer. The immunoprecipitates were fractioned by SDS-PAGE and analyzed by immunobloting as described above.

\section{Immunofluorescence}

HeLa cells $\left(0.25 \times 10^{5}\right)$ were seeded onto sterilized glass coverslips contained in 24-well plates. After transfection, cells were maintained in serum-reduced medium overnight and stimulated with $20 \mathrm{ng} / \mathrm{ml} \mathrm{bFGF}$ for various times. The cells were rinsed with PBS, fixed with $3 \%$ paraformaldehyde in PBS for $15 \mathrm{~min}$ at room temperature, permeabilized with $0.1 \%$ Triton $\mathrm{X}-100$ for $4 \mathrm{~min}$ at room temperature, and washed with PBS. After blocking with $1 \%$ BSA/PBS for $30 \mathrm{~min}$, cells were incubated with the primary antibody (mouse monoclonal anti-Myc (Invitrogen); rabbit polyclonal anti-Sprouty 1 (H120) (Santa Cruz)) for $1 \mathrm{~h}$ at room temperature. After washing with PBS, cells were incubated with the secondary antibody (Alexa Fluor 
488 goat anti-rabbit IgG (Invitrogen); Cy3-conjugated goat anti-mouse IgG (dianova)) for $\mathrm{l} \mathrm{h}$ at room temperature. After the final wash each coverslip was prepared for microscopic examination by applying mounting medium (Mowiol, Hoechst AG).

\section{Luciferase Assay}

Cells were transfected by TransFectin Lipid reagent (Biorad) and Luciferase activity in cell lysates was measured by using the Promega-Luciferase assay system in a Berthold Lumat LB 9501 luminometer. In all reporter assays, $2.5 \times$ $10^{5} \mathrm{HeLa}$ or C33A cells or $1.8 \times 10^{5} \mathrm{NIH}-3 \mathrm{~T} 3$ cells were plated on 6-well dishes.

\section{Statistics}

All measured values are expressed as the mean \pm S.E.M. The significance of the results was analyzed using Student's t-test.

\begin{abstract}
Acknowledgements
We thank Dr. G. Christofori for kindly providing us with mouse Spry 1 and Spry2 CDNA in the pSG9M plasmid, Dr. A. Yoshimura for mouse Spry4 expression vector and Drs. D.J. McCance and K. Lowinski for the GSTE7pGEX-2t construct. We also thank Claudine Kuehn for experimental assistance, Dr. Yixing Zhou and Dr. Steve Shears for helpful discussions and Jennifer Mitchell Zemo for careful proof reading of the manuscript.
\end{abstract}

\section{Author details}

'Laboratory of Signal Transduction, National Institute of Environmental Health Sciences, Research Triangle Park, PO Box 12233, Durham, NC 27709, USA. ${ }^{2}$ Institute for Molecular Biology (Cancer Research), University of Essen, Medical School, Hufelandstrasse 55, 45122 Essen; Germany.

\section{Authors' contributions}

AZ carried out most of the experiments and wrote the manuscript. US participated in performing immunoblots and luciferase assays. HE was the supervisor of AZ, contributed to the intellectual design of the project and in the design of the manuscript. All of the authors read and approved the final version of this manuscript.

\section{Competing interests}

The authors declare that they have no competing interests.

Received: 24 January 2011 Accepted: 26 April 2011 Published: 26 April 2011

\section{References}

1. Berk AJ: Adenovirus promoters and E1A transactivation. Annu Rev Genet 1986, 20:45-79.

2. Brockmann D, Esche H: Regulation of viral and cellular gene expression by E1A proteins encoded by the oncogenic adenovirus type 12. Curr Top Microbiol Immunol 1995, 199(Pt 3):81-112.

3. Gallimore PH, Turnell AS: Adenovirus E1A: remodelling the host cell, a life or death experience. Oncogene 2001, 20:7824-7835.

4. White E: Regulation of p53-dependent apoptosis by E1A and E1B. Curr Top Microbiol Immunol 1995, 199(Pt 3):34-58

5. Wienzek S, Roth J, Dobbelstein M: E1B 55-kilodalton oncoproteins of adenovirus types 5 and 12 inactivate and relocalize $p 53$, but not $p 51$ or p73, and cooperate with E4orf6 proteins to destabilize p53. J Virol 2000, 74:193-202.

6. Williams J, Williams M, Liu C, Telling G: Assessing the role of E1A in the differential oncogenicity of group $\mathrm{A}$ and group $\mathrm{C}$ human adenoviruses. Curr Top Microbiol Immunol 1995, 199(Pt 3):149-175.
7. Sawada Y, Fujinaga K: Mapping of adenovirus 12 mRNA's transcribed from the transforming region. J Virol 1980, 36:639-651.

8. Arany Z, Newsome D, Oldread E, Livingston DM, Eckner R: A family of transcriptional adaptor proteins targeted by the E1A oncoprotein. Nature 1995, 374:81-84

9. Ferguson B, Krippl B, Andrisani O, Jones N, Westphal H, Rosenberg M: E1A $13 \mathrm{~S}$ and $12 \mathrm{~S}$ mRNA products made in Escherichia coli both function as nucleus-localized transcription activators but do not directly bind DNA. Mol Cell Biol 1985, 5:2653-2661.

10. Li Y, Graham C, Lacy S, Duncan AM, Whyte P: The adenovirus E1Aassociated $130-\mathrm{kD}$ protein is encoded by a member of the retinoblastoma gene family and physically interacts with cyclins $\mathrm{A}$ and E. Genes Dev 1993, 7:2366-2377.

11. Turnell AS, Mymryk JS: Roles for the coactivators CBP and p300 and the $\mathrm{APC} / \mathrm{C}$ E3 ubiquitin ligase in E1A-dependent cell transformation. $\mathrm{Br} J$ Cancer 2006, 95:555-560.

12. Whyte P, Buchkovich K, Horowitz JM, Friend SH, Raybuck M, Weinberg RA, Harlow E: Association between an oncogene and an anti-oncogene: the adenovirus E1A proteins bind to the retinoblastoma gene product. Nature 1988, 334:124-129.

13. Madison DL, Yaciuk P, Kwok RP, Lundblad JR: Acetylation of the adenovirus-transforming protein E1A determines nuclear localization by disrupting association with importin-alpha. J Biol Chem 2002, 277:38755-38763.

14. Fax P, Carlson CR, Collas P, Tasken K, Esche H, Brockmann D: Binding of PKA-Rllalpha to the Adenovirus E1A12S oncoprotein correlates with its nuclear translocation and an increase in PKA-dependent promoter activity. Virology 2001, 285:30-41.

15. Sang N, Severino A, Russo P, Baldi A, Giordano A, Mileo AM, Paggi MG, De Luca A: RACK1 interacts with E1A and rescues E1A-induced yeast growth inhibition and mammalian cell apoptosis. J Biol Chem 2001, 276:27026-27033.

16. Severino A, Baldi A, Cottone G, Han M, Sang N, Giordano A, Mileo AM, Paggi MG, De Luca A: RACK1 is a functional target of the E1A oncoprotein. J Cell Physiol 2004, 199:134-139.

17. Turnell AS, Grand RJ, Gorbea C, Zhang X, Wang W, Mymryk JS, Gallimore PH: Regulation of the $26 \mathrm{~S}$ proteasome by adenovirus E1A. Embo J 2000, 19:4759-4773.

18. Casci T, Vinos J, Freeman M: Sprouty, an intracellular inhibitor of Ras signaling. Cell 1999, 96:655-665.

19. Hacohen N, Kramer S, Sutherland D, Hiromi Y, Krasnow MA: sprouty encodes a novel antagonist of FGF signaling that patterns apical branching of the Drosophila airways. Cell 1998, 92:253-263.

20. Kim HJ, Bar-Sagi D: Modulation of signalling by Sprouty: a developing story. Nat Rev Mol Cell Biol 2004, 5:441-450.

21. Minowada G, Jarvis LA, Chi CL, Neubuser A, Sun X, Hacohen N, Krasnow MA, Martin GR: Vertebrate Sprouty genes are induced by FGF signaling and can cause chondrodysplasia when overexpressed. Development 1999, 126:4465-4475.

22. Impagnatiello MA, Weitzer S, Gannon G, Compagni A, Cotten M, Christofori G: Mammalian sprouty-1 and -2 are membrane-anchored phosphoprotein inhibitors of growth factor signaling in endothelial cells. J Cell Biol 2001, 152:1087-1098.

23. Gross I, Bassit B, Benezra M, Licht JD: Mammalian sprouty proteins inhibit cell growth and differentiation by preventing ras activation. $J$ Biol Chem 2001, 276:46460-46468.

24. Chambers D, Mason I: Expression of sprouty2 during early development of the chick embryo is coincident with known sites of FGF signalling. Mech Dev 2000, 91:361-364

25. Klein OD, Minowada G, Peterkova R, Kangas A, Yu BD, Lesot H, Peterka M, Jernvall J, Martin GR: Sprouty genes control diastema tooth development via bidirectional antagonism of epithelial-mesenchymal FGF signaling. Dev Cell 2006, 11:181-190.

26. Guy GR, Wong ES, Yusoff P, Chandramouli S, Lo TL, Lim J, Fong CW: Sprouty: how does the branch manager work? J Cell Sci 2003, 116:3061-3068.

27. Tefft JD, Lee M, Smith S, Leinwand M, Zhao J, Bringas P Jr, Crowe DL, Warburton D: Conserved function of mSpry-2, a murine homolog of Drosophila sprouty, which negatively modulates respiratory organogenesis. Curr Biol 1999, 9:219-222. 
28. Hanafusa H, Torii S, Yasunaga T, Nishida E: Sprouty1 and Sprouty2 provide a control mechanism for the Ras/MAPK signalling pathway. Nat Cell Biol 2002, 4:850-858.

29. Lim J, Yusoff P, Wong ES, Chandramouli S, Lao DH, Fong CW, Guy GR: The cysteine-rich sprouty translocation domain targets mitogen-activated protein kinase inhibitory proteins to phosphatidylinositol 4,5bisphosphate in plasma membranes. Mol Cell Biol 2002, 22:7953-7966.

30. Fong CW, Leong HF, Wong ES, Lim J, Yusoff P, Guy GR: Tyrosine phosphorylation of Sprouty2 enhances its interaction with $\mathrm{c}-\mathrm{Cbl}$ and is crucial for its function. J Biol Chem 2003, 278:33456-33464.

31. Mason JM, Morrison DJ, Bassit B, Dimri M, Band H, Licht JD, Gross I: Tyrosine phosphorylation of Sprouty proteins regulates their ability to inhibit growth factor signaling: a dual feedback loop. Mol Biol Cell 2004, $15: 2176-2188$

32. Hanafusa H, Torii S, Yasunaga T, Matsumoto K, Nishida E: Shp2, an SH2containing protein-tyrosine phosphatase, positively regulates receptor tyrosine kinase signaling by dephosphorylating and inactivating the inhibitor Sprouty. J Biol Chem 2004, 279:22992-22995.

33. Tefft D, Lee M, Smith S, Crowe DL, Bellusci S, Warburton D: mSprouty2 inhibits FGF10-activated MAP kinase by differentially binding to upstream target proteins. Am J Physiol Lung Cell Mol Physiol 2002, 283 L700-706.

34. Lo TL, Yusoff P, Fong CW, Guo K, McCaw BJ, Phillips WA, Yang H, Wong ES, Leong $H F$, Zeng $Q$, et al: The ras/mitogen-activated protein kinase pathway inhibitor and likely tumor suppressor proteins, sprouty 1 and sprouty 2 are deregulated in breast cancer. Cancer Res 2004, 64:6127-6136

35. Kwabi-Addo B, Wang J, Erdem H, Vaid A, Castro P, Ayala G, Ittmann M: The expression of Sprouty1, an inhibitor of fibroblast growth factor signal transduction, is decreased in human prostate cancer. Cancer Res 2004 64:4728-4735.

36. Bloethner $\mathrm{S}$, Chen B, Hemminki K, Muller-Berghaus J, Ugurel $\mathrm{S}$, Schadendorf D, Kumar R: Effect of common B-RAF and N-RAS mutations on global gene expression in melanoma cell lines. Carcinogenesis 2005, 26:1224-1232.

37. Sutterluty H, Mayer CE, Setinek U, Attems J, Ovtcharov S, Mikula M, Mikulits W, Micksche M, Berger W: Down-regulation of Sprouty2 in nonsmall cell lung cancer contributes to tumor malignancy via extracellular signal-regulated kinase pathway-dependent and -independent mechanisms. Mol Cancer Res 2007, 5:509-520.

38. Fong CW, Chua MS, McKie AB, Ling SH, Mason V, Li R, Yusoff P, Lo TL, Leung HY, So SK, Guy GR: Sprouty 2, an inhibitor of mitogen-activated protein kinase signaling, is down-regulated in hepatocellular carcinoma. Cancer Res 2006, 66:2048-2058.

39. King JA, Straffon AF, D'Abaco GM, Poon CL, I ST, Smith CM, Buchert M, Corcoran NM, Hall NE, Callus BA, et al: Distinct requirements for the Sprouty domain for functional activity of Spred proteins. Biochem J 2005, 388:445-454

40. Wakioka T, Sasaki A, Kato R, Shouda T, Matsumoto A, Miyoshi K, Tsuneoka M, Komiya S, Baron R, Yoshimura A: Spred is a Sprouty-related suppressor of Ras signalling. Nature 2001, 412:647-651.

41. Chellappan S, Kraus VB, Kroger B, Munger K, Howley PM, Phelps WC, Nevins JR: Adenovirus E1A, simian virus 40 tumor antigen, and human papillomavirus E7 protein share the capacity to disrupt the interaction between transcription factor E2F and the retinoblastoma gene product. Proc Natl Acad Sci USA 1992, 89:4549-4553.

42. Dyson N, Guida P, Munger K, Harlow E: Homologous sequences in adenovirus E1A and human papillomavirus E7 proteins mediate interaction with the same set of cellular proteins. J Virol 1992, 66:6893-6902.

43. de Groot R, Foulkes N, Mulder M, Kruijer W, Sassone-Corsi P: Positive regulation of jun/AP-1 by E1A. Mol Cell Biol 1991, 11:192-201.

44. Kitabayashi I, Chiu R, Gachelin G, Yokoyama K: E1A dependent upregulation of c-jun/AP-1 activity. Nucleic Acids Res 1991, 19:649-655.

45. Rubin $C$, Zwang $Y$, Vaisman N, Ron D, Yarden Y: Phosphorylation of carboxyl-terminal tyrosines modulates the specificity of Sprouty-2 inhibition of different signaling pathways. J Biol Chem 2005, 280:9735-9744.

46. Berk AJ: Recent lessons in gene expression, cell cycle control, and cell biology from adenovirus. Oncogene 2005, 24:7673-7685.
47. Tsumura Y, Toshima J, Leeksma OC, Ohashi K, Mizuno K: Sprouty-4 negatively regulates cell spreading by inhibiting the kinase activity of testicular protein kinase. Biochem J 2005, 387:627-637.

48. Edwin F, Anderson $K$, Ying C, Patel TB: Intermolecular interactions of Sprouty proteins and their implications in development and disease. Mol Pharmacol 2009, 76:679-691.

49. Hall $A B$, Jura N, DaSilva J, Jang YJ, Gong D, Bar-Sagi D: hSpry2 is targeted to the ubiquitin-dependent proteasome pathway by c-Cbl. Curr Biol 2003, 13:308-314.

50. Edwin F, Patel TB: A novel role of Sprouty 2 in regulating cellular apoptosis. J Biol Chem 2008, 283:3181-3190.

doi:10.1186/1743-422X-8-192

Cite this article as: Zaremba et al:: Sprouty is a cytoplasmic target of adenoviral E1A oncoproteins to regulate the receptor tyrosine kinase signalling pathway. Virology Journal 2011 8:192.

\section{Submit your next manuscript to BioMed Central and take full advantage of:}

- Convenient online submission

- Thorough peer review

- No space constraints or color figure charges

- Immediate publication on acceptance

- Inclusion in PubMed, CAS, Scopus and Google Scholar

- Research which is freely available for redistribution

Submit your manuscript at www.biomedcentral.com/submit
Biomed Central 